\title{
Uma análise comparativa da relação entre o comércio exterior e o crescimento econômico do Rio Grande do Sul e do Brasil (2003-2015)
}

\author{
Ciana Fontana Triches* \\ Divanildo Triches***
}

\begin{abstract}
Resumo
Este artigo tem como objetivo analisar a relação entre o comércio exterior e o crescimento econômico do Rio Grande do Sul e do Brasil ao longo do período de 2003 a 2015. A metodologia empregada é a análise das estatísticas descritivas de dados secundários extraídos de órgãos governamentais e instituições internacionais. Os resultados mostram que o tamanho da economia do estado representa em torno de 7\% do total do país, desse, o setor de serviços participa com $60 \%$, segmento industrial como, aproximadamente, um quarto. A dinâmica de crescimento econômico foi bastante similar com uma taxa média anual de $2,2 \%$. As exportações nacionais e gaúchas cresceram, em média anual, cerca de $8 \%$ e as importações nacionais se elevaram quatro pontos percentuais acima do RS. A correlação mais alta foi verificada entre a taxa de crescimento do produto e o aumento das exportações, com um coeficiente de 0,72 do Rio Grande do Sul e de 0,86 do Brasil. A taxa de câmbio real apresentou uma baixa correlação como com a exportações, além de exibir sinal contrário do esperado. Assim, ao longo do período de 2003 a 2015, o que mais tendeu a influenciar o comércio externo foram os preços internacionais dos produtos comercializados.
\end{abstract}

Palavras-chave: Comércio exterior. Crescimento econômico. Economia brasileira. Estado do Rio Grande do Sul.

* Bacharela em Administração de Empresas em Comércio Exterior pela Universidade do Vale do Rio dos Sinos (Unisinos). Affiliate Manager - AsianBge - Malta. E-mail: cianafontana@hotmail.com

** Doutor em Economia pela Universidade Federal do Rio Grande do Sul. Professor e Pesquisador no Programa de Pós-Graduação em Economia da Universidade do Vale do Rio dos Sinos, PPGE/Unisinos e PQ/CNPq. E-mail: divanildo@pq.cnpqbr e divanildot@unisinos.br 


\section{Introdução}

A partir da década de 1990, o Brasil passou por mudanças significativas na política de comércio exterior. A reformulação dos incentivos às exportações, a redução das barreiras tarifárias e não tarifárias e a implementação de acordos comercias foram fatores que impulsionaram ingresso externo da economia brasileira. Dessa forma, o Brasil tornou-se a sexta economia mundial em 2011, segundo o FEM (2012). Entre os estados brasileiros com maior participação na renda nacional, encontra-se o Rio Grande do Sul, que esteve na quarta posição em 2011, com aproximadamente 6,6\% do Produto Interno Bruto (PIB) brasileiro. Tais dados incidem a elevada integração da economia gaúcha ao mercado nacional, em termos tanto em processo produtivo como em fluxo comercial e internacional. Contudo, em 2015, mesmo o Brasil decaindo o seu posicionamento na economia mundial, o Rio Grande do Sul manteve a sua participação relativa, conforme a FEE (2014).

O PIB do RS representa em torno de 6,5\% do PIB nacional, ocupando a quarta posição entre os maiores estados brasileiros. Salienta-se que os cinco estados com maior participação no PIB detinham $64,9 \%$ da geração de riqueza do país em 2014. São Paulo é o estado com maior participação no PIB brasileiro, com R $\$ 1.86$ trilhão, ou seja, $32,2 \%$ de participação, seguido por Rio de Janeiro, com 11,6\%, e Minas Gerais, com 8,9\%; a quinta colocação é ocupada pelo Paraná, com 6,0\% de participação, de acordo com o IBGE (2015).

Nesse sentido, o objetivo deste estudo é analisar a relação entre o comércio exterior e o crescimento econômico do Rio Grande do Sul e do Brasil ao longo do período de 2003 a 2015. Especificamente, busca-se avaliar a estrutura do comércio exterior do Rio Grande do Sul em comparação ao país como um todo. O tema justifica-se em função da relevância do comércio internacional como um elemento de desenvolvimento das nações. Assim, torna-se relevante entender a contribuição do comércio exterior do estado para o seu crescimento ${ }^{1}$.

O período compreendido entre 2003 a 2015 foi escolhido com o intuito de analisar possíveis contribuições, mudanças ou efeitos entre os países externos para com o Brasil e o Rio Grande do Sul em um novo cenário político conduzido pelo governo Lula. Segundo Cavalcante e Lima (2013), o governo manteve estabilidade econômica, preservando a gestão macroeconômica como as metas de inflação, a flutuação cambial e a responsabilidade fiscal. Nesse sentido, é possível notar o elevado crescimento de exportações e importações. 
O artigo está organizado, além desta introdução, em três capítulos. O segundo aborda de forma sintética as correntes teóricas mais modernas do comércio internacional. Na terceira seção, é destacada a análise econômica do Brasil e do Rio Grande do Sul. O comércio exterior comparativamente entre o estado gaúcho e o país é avaliado na quarta seção. A análise de correlação e as conclusões são tratadas nas duas seções seguintes.

\section{Correntes teóricas do comércio internacional}

As teorias do comércio internacional procuram explicar as razões pelas quais os países comercializam bens e serviços entre si. Essas teorias mostram que o comércio internacional é benéfico para o crescimento econômico dos países. As abordagens clássicas e neoclássicas dão ênfase, para isso, nas vantagens comparativas na eficiência na produção e em diferenças na dotação de recursos entre os países, respectivamente.

A nova teoria do comércio internacional, por sua vez, contempla as economias de escala em indústrias de concorrência imperfeita. Com isso, passa a admitir o comércio intraindustrial, que se baseia em produtos razoavelmente parecidos entre países. As economias de escalas reduzem os custos médios da produção de cada empresa à medida que a produção da indústria se expande, ou seja, a produção será mais eficiente quanto maior for a escala na qual ela se encontra, conforme Krugman e Obstfeld (2005).

As economias de escala podem ser internas e externas da indústria. As economias internas ocorrem quando o custo por unidade do produto depende do tamanho de uma firma individual, mas não necessariamente de toda a indústria. Portanto, a economia de escala interna leva à concorrência imperfeita, porque elimina a concorrência entre os países, pelo fato de que há uma redução de número de firmas nessa indústria. Já as economias de escala externas da indústria referem-se a quando o custo por unidade do produto depende do tamanho da indústria, mas não da dimensão da empresa em si.

Outra explicação sobre a ocorrência do comércio internacional está associada ao investimento externo, o qual se dá a partir das decisões das empresas. Segundo Knight, Cavusgil e Riesenberger (2010), as corporações instalam determinadas unidades produtivas na busca de escala de produção para produzir e exportar. Para 
isso, Dunning (2001) e Pessoa e Martins (2007) apontam quatro motivações ou estratégias para as empresas tomarem a decisão em instalar unidades produtivas em outros países: a) resource seeking (procura pela disponibilidade de recursos), o que significa a busca por recursos naturais, com custos mais baixos, procura por vantagens locais; b) market seeking (procura por mercado), o investimento direto estrangeiro busca atender os mercados locais dos países hospedeiros por meio das exportações, principalmente os países vizinhos; c) efficiency seeking (procura por eficiência), as empresas multinacionais procuram explorar as economias de escala e escopo, a fim de diversificar os riscos e encontrar maior eficiência no mercado; e) asset/capability seeking (procura por ativos estratégicos), busca por ativos estratégicos que possam se somar às vantagens competitivas ou diminuir o potencial competitivo dos seus concorrentes. Nesse último caso, a dispersão de atividades inovadoras ainda ocorre preferencialmente entre os países desenvolvidos. E é essa a razão principal para que os países emergentes disputem a instalação de subsidiárias e ofereçam componentes de localização adicionais que possam atrair tais atividades. Assim, é necessário atrair investimentos de empresas multinacionais, especialmente em atividades de inovação, que contribuem para a capacitação tecnológica com um esforço concentrado de políticas públicas.

O crescimento e o desenvolvimento econômico podem também ser determinados por fatores diretamente associados ao comércio internacional para o desenvolvimento de uma nação. A liberação comercial entre as nações, segundo Agénor (2000), poderia se constituir como um determinante básico, o qual teria efeitos benéficos sobre o a taxa de crescimento em longo prazo. Para Romer (1994), abertura comercial eleva a produtividade da economia ao conceder acesso a bens intermediários de melhor qualidade ou de menor custo e também aumenta a variedade de bens ofertados no mercado doméstico e, consequentemente, a elevação do bem-estar social.

O crescimento econômico, na concepção de Krugman e Obstfeld (2005), implica um deslocamento para fora da fronteira de possibilidades de produção de um país com efeito no uso mais eficiente dos recursos escassos dos países, que, em última instância, é o resultado da produtividade da economia. O comércio internacional poderá reduzir riscos nos mercados de capitais, podendo o país melhorar a captação de recursos e, por fim, gerar ganhos de economias de escala, devido ao ingresso no mercado mundial. 
O desenvolvimento econômico de uma nação, como afirmam Krugman e Obstfeld (2005), está sujeito a um processo técnico, geralmente classificado como neutro, poupador de mão de obra e capital. Esse conduz a uma redução de quantidade tanto de mão de obra como de capital necessário para produzir qualquer nível de produção. Os processos técnicos geram deslocamento para fora da fronteira de possibilidades, quando há crescimento dos fatores. E, como resultado, os efeitos do crescimento econômico sobre o comércio internacional decorrem em um crescimento enviesado.

A direção dos efeitos sobre os termos de troca depende da natureza do crescimento. Se o crescimento é enviesado para as exportações, significa que aumentará a capacidade de uma economia de produzir bens que estava inicialmente exportando mais do que importando; pioram-se os termos de troca. Entretanto, o crescimento que é enviesado para as importações aumentará desproporcionalmente a capacidade de produzir bens que concorrem com importação; melhoram-se os termos de troca no país. É possível, também, que um crescimento enviesado para importações no estrangeiro prejudique um país, como argumentam Krugman e Obstfeld (2005).

\section{Análise da economia do estado do Rio Grande do Sul e do Brasil}

O comércio exterior tanto do Brasil quanto do Rio Grande do Sul é tratado com fins de avaliar a influência no seu respectivo crescimento econômico. Desse modo, caracteriza-se, incialmente, o desempenho econômico comparativo das atividades do comércio exterior estadual e nacional. O Rio Grande do Sul é considerado um dos estados da federação com elevado grau de industrialização em relação a outras regiões do país, principalmente Norte e Nordeste. De acordo com Feix e Leusin Júnior (2015) e Leitzke e Triches (2010), o estado gaúcho possui sua estrutura produtiva propícia à atividade agrícola e, consequentemente, ao desenvolvimento do agronegócio, aliada à imigração alemã e italiana, que trouxeram conhecimentos preciosos para a execução de atividades manufatureiras que estimularam o desenvolvimento industrial da região.

Os indicadores macroeconômicos, tais como evolução do PIB brasileiro e gaúcho, taxa de crescimento setorial e total do PIB e taxa de participação do Rio Grande de Sul no PIB brasileiro, têm apresentado desempenho positivo entre 2003 e 
2015. Em termos de participação setorial, verifica-se, por meio da Tabela 1, que o setor de serviços, que incorpora a ampliação nas atividades de comércio, transporte, armazenagem, correio e outros serviços, registrou um aumento na participação do total do PIB brasileiro, passando de $\mathrm{R} \$ 64,8$ bilhões, ou $64,8 \%$ do total em 2003 , para $\mathrm{R} \$ 3,75$ trilhões, o equivalente a 72,7\% do total em 2005.

Tabela 1 - Evolução do PIB brasileiro por setor de 2003 a 2015 (em R $\$$ bilhões)

\begin{tabular}{l|r|r|r|r|r|r|r|r}
\hline \multicolumn{1}{c|}{ Ano/ PIB } & \multicolumn{1}{|c|}{2003} & $\begin{array}{c}\text { Part. } \\
(\%)\end{array}$ & 2007 & $\begin{array}{c}\text { Part. } \\
(\%)\end{array}$ & 2011 & \multicolumn{1}{c|}{$\begin{array}{c}\text { Part. } \\
(\%)\end{array}$} & 2015 & \multicolumn{1}{c}{$\begin{array}{c}\text { Part. } \\
(\%)\end{array}$} \\
\hline PIB & $1.470,6$ & 100,0 & $2.287,9$ & 100,0 & $3.530,9$ & 100,0 & $5.154,3$ & 100,0 \\
Agropecuária & 108,6 & 7,4 & 127,3 & 5,6 & 192,6 & 5,5 & 263,6 & 5,0 \\
Indústria & 409,5 & 27.8 & 636,3 & 27,8 & 972,2 & 27,5 & $1.151,5$ & 22,3 \\
Serviços & 952,5 & 64.8 & $1.524,3$ & 66,6 & $2.366,0$ & 67,0 & $3.746,3$ & 72,7 \\
\hline
\end{tabular}

Fonte: IBGE (2015).

O setor industrial, por sua vez, encolheu sua participação em 5,5 pontos percentuais, passando de 27,8\% em 2003 para 22,3\% do total do PIB brasileiro 12 anos mais tarde. O recuo foi mais intenso em 2005, resultado de acordo com o Bacen (2015), da retração da produção em todos os 25 segmentos, em particular os segmentos de equipamentos de informática, veículos automotores, móveis, produtos têxteis e de alimentos. O setor da agropecuária também seguiu a mesma trajetória do setor industrial, embora com uma contração um pouco menor, de 2,4 pontos percentuais no período de 2003 a 2015; a participação desse setor no PIB era de 7,4\% em 2003 e encerrou com $5 \%$ do total, 12 anos após.

A evolução do PIB e seus componentes no estado do Rio Grande do Sul, entre 2003 e 2014, passou de $\mathrm{R} \$ 102,5$ bilhões para $\mathrm{R} \$ 357,8$ bilhões. O setor agropecuário mostrou perda na participação do PIB gaúcho, de 13,7\% em 2003 para 8,3\% em 2011; com um pequeno aumento, para 9,3\%, em 2014. Porém, em valores absolutos, manteve-se em crescimento, acompanhando o aumento do PIB total.

A participação do setor industrial também perdeu espaço na composição do PIB gaúcho. Em 2003, esse setor produzia em torno de $\mathrm{R} \$ 27,4$ bilhões, que representava cerca de um quarto; já em 2014, teve a participação reduzida para um quinto, com uma produção contabilizada em $\mathrm{R} \$ 83,6$ bilhões em preços correntes. $\mathrm{O}$ setor de serviços teve o maior índice de participação no PIB do Rio Grande do Sul, $59,5 \%$ em 2003, com um total de $\mathrm{R} \$ 61,0$ bilhões, alcançando, em $2007,65,7 \%$ na 
participação total do PIB gaúcho. Apesar do aumento do setor de serviços, em 2011 sua participação no PIB total diminuiu cerca de um ponto percentual, contudo, em 2014, novamente elevou sua porcentagem de participação para $67,3 \%$. Da mesma forma, analisando o setor de serviços do Brasil, percebe-se que houve também aumento em participação.

Tabela 2 - Evolução do PIB gaúcho por setor de 2003 a 2014 (em R\$ bilhões)

\begin{tabular}{l|r|r|r|r|r|r|r|r}
\hline \multicolumn{1}{c|}{ Ano/ PIB } & \multicolumn{1}{|c|}{2003} & $\begin{array}{c}\text { Part } \\
(\%)\end{array}$ & 2007 & \multicolumn{1}{c|}{$\begin{array}{c}\text { Part } \\
(\%)\end{array}$} & 2011 & \multicolumn{1}{c|}{$\begin{array}{c}\text { Part } \\
(\%)\end{array}$} & 2014 & $\begin{array}{c}\text { Part } \\
(\%)\end{array}$ \\
\hline PIB & 102,4 & 100,0 & 143,5 & 100,0 & 226,3 & 100 & 357,8 & 100 \\
Agropecuária & 14,1 & 13,7 & 13,0 & 9,1 & 18,9 & 8,3 & 33,4 & 9,3 \\
Indústria & 27,4 & 26,8 & 36,1 & 25,2 & 61,4 & 27,2 & 83,6 & 23,4 \\
Serviços & 61,0 & 59,5 & 94,4 & 65,7 & 146,0 & 64,5 & 240,8 & 67,3 \\
\hline
\end{tabular}

Fonte: IBGE (2015) e FEE (2014).

Salienta-se que a composição setorial do produto do Rio Grande do Sul seguiu a tendência similar observada para a economia do país. Esse fato também é constatado em economias em estágios de desenvolvimento mais avançado, ou seja, quando as economias se desenvolvem, o setor de serviços aumenta sua participação no PIB.

A dinâmica taxa de crescimento da economia brasileira e seus principais componentes foram bastante instáveis ao longo de 2003 a 2015, como ilustra a Figura 1. As maiores elevações do ritmo das atividades econômicas ocorreram em 2007, com $6,10 \%$, e em 2010 , com $7,50 \%$, justamente nos períodos pré e pós-crise internacional. Já as piores taxas ocorreram em 2009, com um crescimento negativo de $0,1 \%$, e em 2015 , com uma queda de $3,8 \%$, a qual culminou na crise política e fiscal, com a perda do mandato da presidente Dilma, como aponta o Bacen (2015). Salienta-se, contudo, que, no período de 2003 a 2015, a economia brasileira acumulou um crescimento de $45,8 \%$, o que representa uma taxa média anual de $2,9 \%$. Observa-se, ainda, que, após 2010, a taxa de crescimento do PIB reduziu-se gradativamente, alcançando uma queda no crescimento, que em 2010 era de $7,50 \%$, para 1,90\% em 2012, devido ao auxílio da queda dos dois setores, o agropecuário e o industrial. Em 2013, apesar do estímulo de crescimento, a taxa do PIB atingiu $3,0 \%$ de crescimento, o que foi sustentado pelo desempenho da agropecuária. Em 2015, o país teve o pior resultado da série considerada. 
Figura 1 - Taxa de crescimento do PIB setorial e total do Brasil de 2003 a 2015 (em \%)

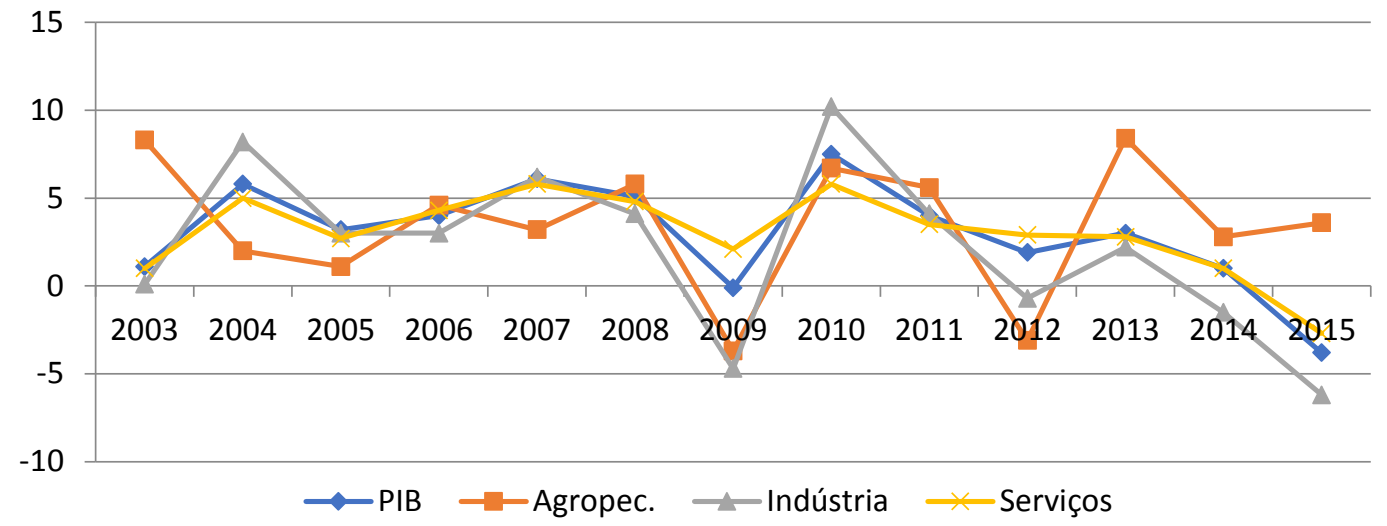

Fonte: IBGE (2015).

Em termos setoriais ou de oferta de bens e serviços, observa-se que eles mantiveram um comportamento bastante similar à evolução do produto total. $\mathrm{O}$ destaque ficou por conta do setor agropecuário, que acumulou 54,8\%, ou uma taxa média anual de 3,4\% no período de 2003 a 2015, portanto meio ponto percentual acima do crescimento médio do PIB. Ressalta-se que esse segmento experimentou condições meteorológicas adversas, com quebras de safras em 2009, alcançando seu pior resultado analisado. No entanto, segundo o Bacen (2013), essas adversidades foram também compensadas pelas supersafras de grãos, como soja, milho e trigo, e pela produção de cana de açúcar, bem como pelo aumento nos abates de bovinos e aves, entre outros fatores já salientados. $\mathrm{O}$ setor de serviços apresentou um desempenho idêntico ao produto, acumulando no período uma elevação de 46,3\%. Já o pior desempenho ficou por conta do setor industrial, o qual apresentou uma dinâmica de crescimento médio anual de 2,0\%, acumulando, no período 2003 a 2015, 30,2\%, ou seja, 15,6 pontos percentuais abaixo da evolução do PIB.

O desempenho da economia gaúcha apresentou um comportamento menos oscilatório do que a economia nacional, com exceção do setor agropecuário entre 2003 e 2015, como mostra a Figura 2, embora a dinâmica de crescimento do PIB tenha exibido um comportamento bastante similar, acumulando no período $32,24 \%$, o que representa também uma média anual de $2,2 \%$. Contudo, o que mais se sobressai é o notável crescimento do setor agropecuário, com uma taxa média superior a 5,4\% ao ano, acumulando no período $87,9 \%$. 
Figura 2 - Taxa de crescimento do PIB setorial e total do Rio Grande do Sul de 2003 a 2014 (em \%)

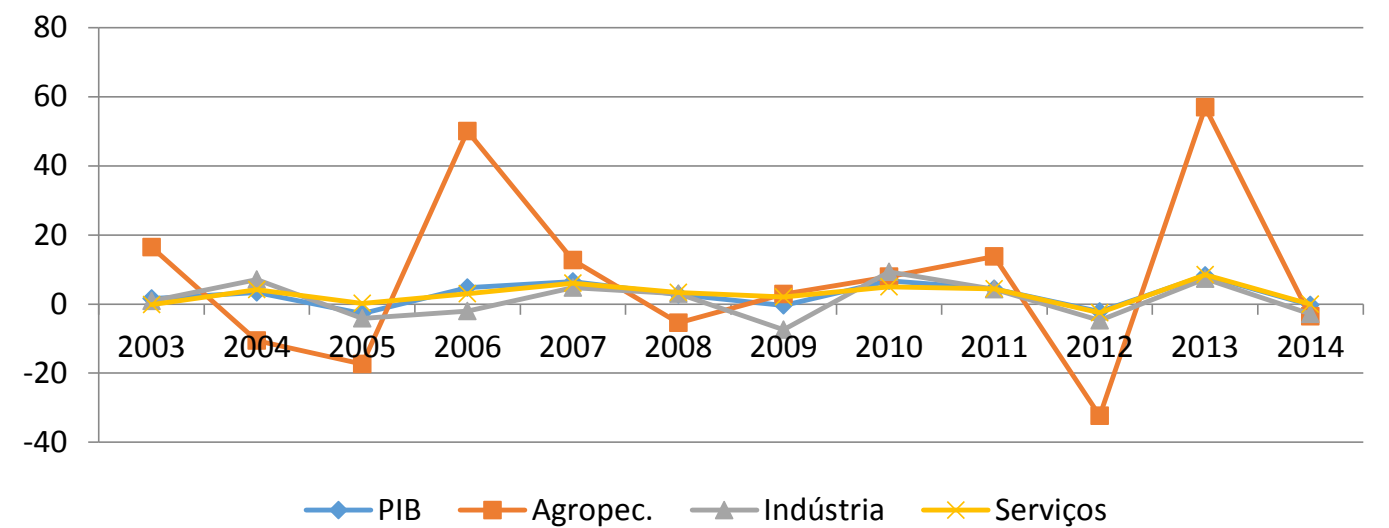

Fonte: IBGE (2015).

Em 2005 e 2012, o setor agropecuário alcançou as maiores retrações do período: $-17,40 \%$ e $-32,40 \%$, respectivamente. A queda deu-se devido ao impacto das adversidades climáticas sobre o produto da agropecuária gaúcha. A redução da safra de arroz, segundo o Bacen (2013), foi provocada pela escassez de chuvas na Região Sul, o que prejudicou a semeadura do cereal no estado. Entretanto, em 2013, a produção de trigo impulsionou o crescimento do setor, em virtude da atratividade das cotações das commodities no período da semeadura do grão, recuperando, assim, o decrescimento em 2012, atingindo 56,96\% de crescimento anual. Dessa forma, o estado do Rio Grande do Sul tornou-se o principal produtor do grão em 2013, com $58,7 \%$ do total da safra nacional, ainda segundo o Bacen (2013).

No que tange ao setor de serviços gaúcho, nota-se um pequeno crescimento acima do PIB no acumulado, no período de 2003 a 2015, de 35,2\%, o que representou uma taxa média anual de 1,02\%. Já o pior desempenho, a exemplo da indústria nacional, ficou por conta do setor industrial gaúcho, que acumulou no período apenas 2,0\%, com uma média anual muito baixa, ou seja, de $0,15 \%$. Além disso, é possível observar que a economia gaúcha, em 2014, perdeu dinamicidade e obteve um decrescimento.

As participações do PIB e dos seus respectivos componentes do Rio Grande do Sul em relação ao do Brasil, ao longo do período de 2003 a 2014, estão reportadas na Figura 3. Nota-se que a participação do PIB gaúcho tem sempre oscilado entre 7,0\% e 8,0\% do total nacional, e em 2014 essa participação ficou em torno de 6\%. Os setores de indústria e serviços mantiveram-se estáveis com a participação pouco abaixo do produto total, isto é, oscilando entre $7 \%$ e $6 \%$ ao logo das séries analisadas. 
Figura 3 - Participação do PIB setorial e total do Rio Grande do Sul no Brasil de 2003 a 2014 (em \%)

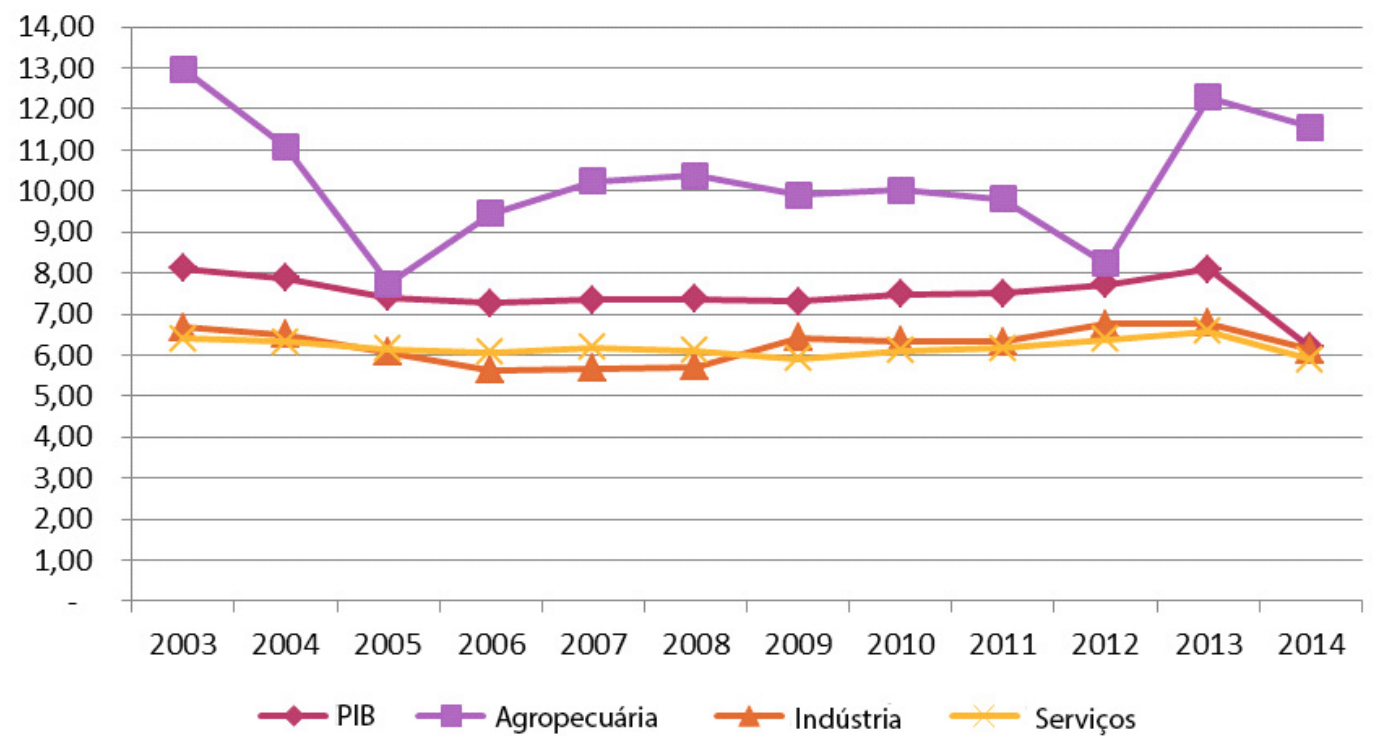

Fonte: IBGE (2015) e FEE (2014).

Evidentemente, foram constatadas grandes oscilações na taxa de participação do setor agropecuário, iniciando o período, em 2003, com a taxa elevada, em $13 \%$ de participação no setor agropecuário brasileiro. Entretanto, tal percentual recuou gradativamente, até alcançar 8,0\% em 2005, mantendo-se assim até 2012. Com a retomada da atividade em 2013, o setor agropecuário gaúcho elevou-se, acompanhando o crescimento do setor brasileiro, atingindo sua segunda maior taxa de participação, com $12 \%$.

\section{Avaliação do comércio externo gaúcho e brasileiro}

A pauta exportadora brasileira é caraterizada como altamente concentrada e especializada em recursos naturais e de bens de baixo conteúdo tecnológico, como mostram Storti, Langoski e Florianovitch (2012). Essa regra também é similar para o estado do Rio Grande do Sul, que é a terceira unidade da federação que mais exporta, ficando atrás somente de São Paulo e Minas Gerais. Por outro lado, o Rio Grande do Sul é o quinto maior comprador de produtos externos, perfazendo $5,84 \%$ do total das importações brasileiras, perdendo apenas para São Paulo, Rio de Janeiro, Santa Catarina e Paraná. 
A comparação da evolução do comércio exterior do Brasil e do estado do Rio Grande do Sul, bem como das respectivas taxas de crescimento, ao longo do período de 2003 a 2015, é ilustrada na Tabela 3. Nota-se que o saldo da balança comercial brasileira apresentou superávit em 2003 de US $\$ 28,35$ bilhões, contra US $\$ 3,84$ bilhões do estado. Em 2015, a balança comercial registrou o menor superávit dos 12 anos anteriores. O resultado decorreu com exportações totalizando US $\$ 191,13$ bilhões e importações totalizando US $\$ 171,45$ bilhões, encerrando com um saldo comercial de US $\$ 19,685$ bilhões. A redução das exportações e importações do Brasil, em 2015, refletiu um cenário econômico envolvido na recessão, segundo o Bacen (2015), sendo que houve aumento de tarifas, retirada de subsídios e incentivos fiscais. Além disso, com a normalização da política monetária nos EUA e a deterioração das perspectivas de crescimento global brasileiro, ocorreram o declínio nos preços de commodities e a desvalorização na taxa de câmbio, como cita o Bacen (2015), sendo que a taxa de câmbio nominal iniciou o ano em desvalorização de $47,0 \%$ no ano, passando de $\mathrm{R} \$ 2,65$, ao final de 2014 , para $\mathrm{R} \$ 3,90$ por dólar norte-americano, ao final de 2015.

Tabela 3 - Balança comercial - evolução do comércio exterior do Brasil e do Rio Grande do Sul entre 2003 e 2015 (em US\$ milhões)

\begin{tabular}{|c|c|c|c|c|c|}
\hline \multirow{2}{*}{ Conta/Ano } & 2003 & 2007 & 2011 & 2015 & $\operatorname{Var} .(\%)^{*}$ \\
\hline & \multicolumn{5}{|c|}{ Brasil } \\
\hline $\begin{array}{l}\text { Exportação } \\
\text { Importação } \\
\text { Saldo }\end{array}$ & $\begin{array}{l}\text { 73.203, } \\
44.848, \\
28.355\end{array}$ & $\begin{array}{r}160.649 \\
120.617 \\
40.032\end{array}$ & $\begin{array}{r}256.039 \\
226.246 \\
29.793 \\
\end{array}$ & $\begin{array}{r}191.134 \\
171.449 \\
19.685 \\
\end{array}$ & $\begin{array}{r}8,33 \\
11,82 \\
-3,00 \\
\end{array}$ \\
\hline \multicolumn{6}{|c|}{ Rio Grande do Sul } \\
\hline Exportação & 8.027, & 15.017 & 19.427, & 17.518, & 6,72 \\
\hline Importação & 4.190, & 10.168, & 15.662, & 10.020, & 7,54 \\
\hline Saldo & 3.837, & 4.849, & 3.765, & 7.498, & 5,74 \\
\hline $\begin{array}{l}\text { Exportações } \\
\text { RS/BR (\%) }\end{array}$ & 10,97 & 9,35 & 7,59 & 9,17 & $-1,48$ \\
\hline $\begin{array}{l}\text { Importações } \\
\text { RS/BR (\%) }\end{array}$ & 8,67 & 8,43 & 6,92 & 5,84 & $-3,23$ \\
\hline
\end{tabular}

Fonte: AliceWEB e SECEX/MDIC.

* Média geométrica de crescimento anual.

Em geral, observa-se que as exportações passaram de US\$ 73,20 bilhões em 2003 para US $\$ 191,134$ bilhões 12 anos mais tarde, o que representou um crescimento médio anual de $8,33 \%$. As importações mostram um aumento ainda mais acentuado 
de $11,82 \%$, ou seja, cresceram de US $\$ 44,85$ bilhões para US $\$ 171,45$ bilhões. Como resultado, em 2015, o saldo comercial reduziu-se em aproximadamente $25 \%$ em apenas quatro anos, mostrando que o saldo comercial se encolheu numa média anual de 3,0\%, embora esse valor tenha quase duplicado no intervalo de 2003 a 2007.

No Rio Grande do Sul, os níveis de crescimento de exportações e importações equipararam-se com os do Brasil, ou seja, de 2003 a 2011, houve um aumento de aproximadamente 59\% nas exportações, de US\$ 8,03 bilhões em 2003 para US\$ 19,43 bilhões em 2011. No ano de 2015, a queda das exportações e importações do estado gaúcho foi de $9,7 \%$ e $5,8 \%$ em relação a 2011, respectivamente. Porém, como as importações reduziram mais do que as exportações, o saldo da balança, em 2015, obteve o melhor resultado dos períodos analisados, registrando superávit de US\$ 7,50 bilhões. Todavia, o resultado do saldo da balança comercial diferiu do saldo do Brasil, com um crescimento de 5,74\% entre 2003 e 2015.

A participação do estado gaúcho nas exportações e importações do Brasil, de 2003 a 2015, é visualizada por meio da Tabela 3 e da Figura 6. Observa-se que, de 2003 a 2004, a participação do estado esteve em torno de $10 \%$ nas exportações, porém, a partir de 2005, houve uma queda considerável. A menor participação apontada no período analisado foi em 2012, com 7,17\%. Nota-se que, entre 2003 a 2013, as participações das exportações do Rio Grande do Sul só decaíram, com exceção do ano de 2013, que rapidamente alcançou a taxa de 2003, encerrando $2015 \mathrm{com}$ $9,17 \%$ do total nacional. Quanto à participação das importações do estado gaúcho em relação ao total do país, essa passou de 8,67\% em 2003 para 5,84\% doze anos mais tarde, tendo uma redução de 3,23 pontos percentuais.

Figura 6 - Participação das exportações e importações gaúchas no Brasil no período de 2003 a $2015(\%)$

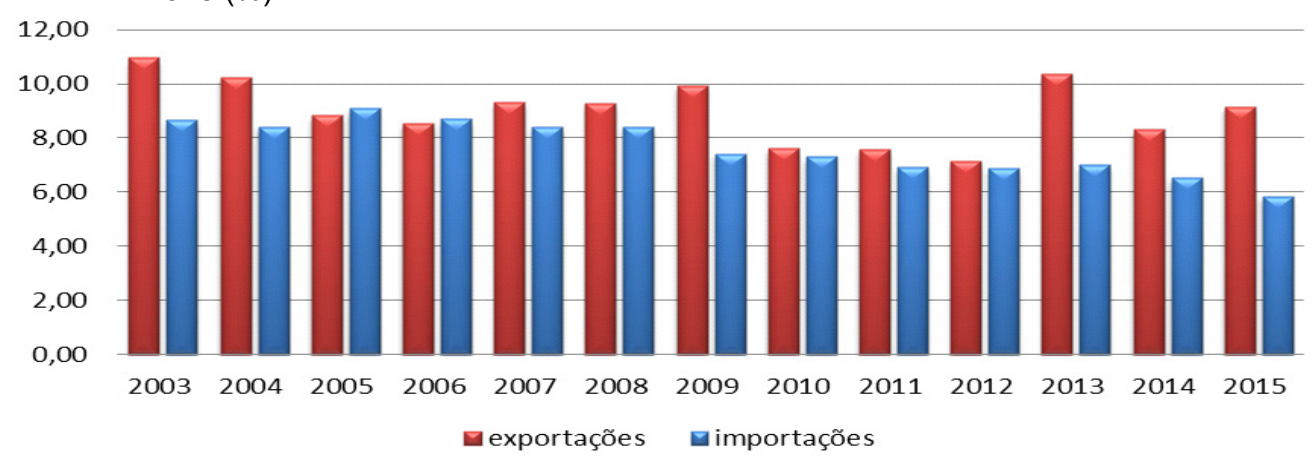

Fonte: AliceWEB e SECEX/MDIC.

Teoria e Evidência Econômica - a. 25, n. 52, p. 7-28, jan./jun. 2019 
Os principais países a que se destinam as exportações brasileira e gaúcha no período de 2003 a 2015 são destacados nas Figuras 7 e 8. Em geral, os destinos da exportação brasileira mantiveram-se para os mesmos países, apenas houve uma alteração das posições. Assim, em 2003, apareciam os Estados Unidos com 24\% do total, após despontavam Argentina e China com 7\% e 6\%, respectivamente. Já em 2015, a China passou para a primeira posição, com 19\%, Estados Unidos ficou em segundo lugar, com 13\%, e a Argentina em terceiro, mantendo os mesmos 7\% do total das vendas externas do país. Os demais países permaneceram com a mesma proporção, ou seja, 53\% do total. Segundo Pereira (2011), a crise mundial de 2008 impactou o Brasil em 2009, causando um declínio das exportações totais. Dessa forma, os principais destinos do país, como Estados Unidos e Europa, passaram a se recuperar de forma mais lenta em comparação ao crescimento chinês.

Figura 7 - Participação dos principais países de destino das exportações do Brasil em 2003 e $2015(\%)$
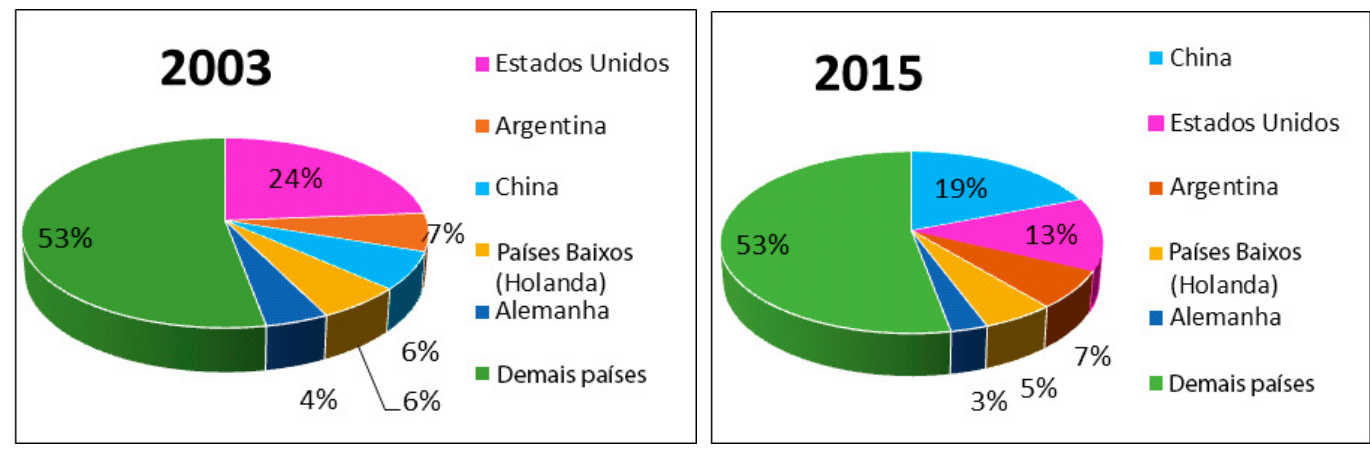

Fonte: Secex/Mdic.

Os destinos mais relevantes das exportações gaúchas encontram-se na Figura 8. Nota-se que, em 2003, os Estados Unidos tiveram participação de $22 \%$, cerca de US\$ 1,780 bilhão; em 2007, US\$ 1,772 bilhão; já em 2015, na posição de terceiro maior destino exportador do Rio Grande do Sul, representava uma participação de apenas 7,26\%, cerca de US\$1,189 bilhão. Segundo Lamas (2007), os Estados Unidos perderam participação por conta do aumento das compras chinesas. Assim, em 2003, a China detinha 9\%, cerca de US $\$ 719,140$ milhões do total exportado; já em 2007, respondeu por US\$1,471 bilhão.

Em 2015, além de liderar a posição de maior destino das exportações brasileiras, a China também continuou como a maior destinatária das exportações gaúchas, respondendo por $28 \%$ das vendas externas totais. A principal demanda desse 
país encontra-se por commodities agrícolas, que contribuem para o aumento das exportações gaúchas de produtos primários, os quais se caracterizam por apresentarem baixo valor agregado, conforme mostram Feix e Leusin Júnior (2015).

Figura 8 - Participação dos principais países de destino das exportações do Rio Grande do Sul em 2003 e $2015(\%)$
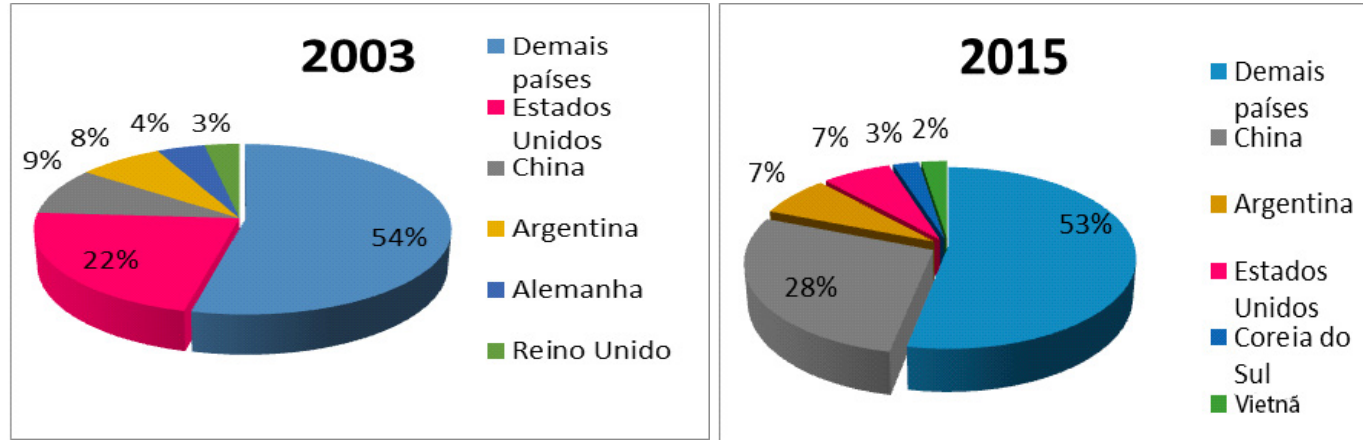

Fonte: Secex/Mdic (2015).

Observa-se, ainda, por meio da Figura 8, que as exportações que se destinaram à Argentina passaram de US\$ 606,98 milhões, ou seja, 7\% em 2003, para US\$1,27 bilhão, 12 anos mais tarde. Logo, houve crescimento das exportações destinadas aos argentinos, que subiram uma posição, de terceira em 2003 para segunda em 2015.

No que concerne aos perfis comerciais do Brasil e do Rio Grande do Sul, ao longo de 2003 a 2015, nas Tabelas 6 e 7, percebe-se que o complexo de soja lidera as exportações. No caso nacional, ele passou de US\$ 4,29 bilhões, ou 5,9\% do total, em 2003 para US\$20,98 bilhões, ou 15,57\%, 12 anos mais tarde. Em seguida, aparecem os segmentos de minérios de ferro, que mais do que duplicaram a participação no período. Na terceira posição, despontava automóveis de passageiros com 3,65\% da pauta, em 2003. Já, em 2015, eles saíram da lista dos cinco principais produtos, assumindo em seu lugar os produtos de óleos brutos de petróleo, com 8,74\% do total exportado, que em 2003 estava na quinta posição. Outro segmento que perdeu participação foi farelo e resíduos de óleo de soja, o qual se encontrava na quarta colocação em 2003, com 3,56\% da pauta, e passou para a sexta, com 4,32\%, 12 anos depois. A carne de frango e o açúcar de cana somente passaram a compor a relação em 2015, ficando em quarto e quinto lugares, com uma participação de 4,62\% e $4,36 \%$, respectivamente, do montante vendido ao exterior. 
Tabela 6 - Principais produtos exportados pelo Brasil entre 2003 e 2015 (em US\$ bilhões FOB)

\begin{tabular}{|c|c|c|c|c|c|c|}
\hline Posição* & Produtos 2003 & Valor & $(\%)$ & Produtos 2015 & Valor & $(\%)$ \\
\hline $1 \stackrel{0}{1}$ & Complexo de soja & 4,290 & 5,90 & Complexo de soja & 20,984 & 15,57 \\
\hline $2^{\circ}$ & Minérios de ferro & 3,454 & 4,73 & Minérios de ferro & 14,076 & 10,45 \\
\hline $3^{\circ}$ & Automóveis de passageiros & 2,656 & 3,63 & $\begin{array}{l}\text { Óleos brutos de } \\
\text { petróleo }\end{array}$ & 11,781 & 8,74 \\
\hline $4^{\circ}$ & $\begin{array}{l}\text { Farelo e resíduos de óleo } \\
\text { de soja }\end{array}$ & 2,602 & 3,56 & Carne de frango & 6,230 & 4,62 \\
\hline $5^{\circ}$ & Óleos brutos de petróleo & 2,122 & 2,90 & Açúcar de cana & 5,901 & 4,38 \\
\hline \multirow[t]{2}{*}{$6^{\circ}$} & Aviões & 1,938 & 2,65 & $\begin{array}{l}\text { Farelo e resíduos } \\
\text { de óleo de soja }\end{array}$ & 5,821 & 4,32 \\
\hline & Demais produtos & 56,019 & 76,63 & Demais produtos & 69,959 & 51,92 \\
\hline
\end{tabular}

Fonte: Secex/Mdic.

* Posição com base no ano de 2015.

Tabela 7 - Principais produtos exportados pelo Rio Grande do Sul entre 2003 e 2015 (em US\$ milhões FOB)

\begin{tabular}{|c|c|c|c|c|c|c|}
\hline Posição* & Produtos 2003 & Valor & $(\%)$ & Produtos 2015 & Valor & $(\%)$ \\
\hline $1^{0}$ & Complexo de soja & 839,3 & 10,50 & Complexo de soja & $4.094,4$ & 26,20 \\
\hline $2^{\circ}$ & Calçados de couro natural & 797,3 & 9,95 & Fumo & $1.271,1$ & 8,13 \\
\hline $3^{\circ}$ & Fumo & 726,3 & 9,06 & $\begin{array}{l}\text { Farelo e resíduos do } \\
\text { óleo de soja }\end{array}$ & 979,4 & 6,26 \\
\hline $4^{\circ}$ & $\begin{array}{l}\text { Farelo e resíduos do óleo } \\
\text { de soja }\end{array}$ & 353,1 & 4,41 & Carnes de frango & 719,8 & 4,60 \\
\hline $5^{\circ}$ & Óleo de soja & 255,8 & 3,18 & $\begin{array}{l}\text { Pedaços e miudezas } \\
\text { de carne de frango }\end{array}$ & 414,4 & 2,65 \\
\hline \multirow[t]{2}{*}{$6^{\circ}$} & Carne de frango & 247,5 & 3,10 & $\begin{array}{l}\text { Plataformas de per- } \\
\text { furação }\end{array}$ & 394,2 & 2,52 \\
\hline & Demais produtos & $4.793,9$ & 59,8 & Demais produtos & $7.761,5$ & 49,64 \\
\hline
\end{tabular}

Fonte: Secex/Mdic (2015).

* Posição com base no ano de 2015

O complexo de soja aumentou consideravelmente sua participação da pauta das exportações do Rio Grande do Sul, passando de 10,50\% para 26,2\%, ou seja, uma elevação de 15,7 pontos percentuais. Na segunda e na terceira colocações, em 2003, apareciam calçados de couro com $10 \%$ e fumo com $9 \%$ do total das vendas externas do estado gaúcho. A demanda desses produtos está voltada especialmente para China, Argentina e Estados Unidos. Já, em 2015, calçados de couro deixou a relação dos principais produtos exportados pelo estado, e o fumo assumiu a 
segunda posição. Em seguida, encontra-se o setor farelo e resíduos do óleo de soja, com $6,26 \%$. Salienta-se que o complexo de soja e derivados perfazem aproximadamente um terço do total das exportações em 2015, contra cerca de $15 \%$ de 12 anos antes.

Por fim, em 2015, é possível verificar a participação na quarta posição das carnes, com 4,6\% de participação total. Com o aumento do fluxo comercial brasileiro, percebem-se a influência no fluxo comercial do Rio Grande do Sul e a ampliação em produtos oriundos do agronegócio.

\section{Análise de correlação}

No sentido de avaliar a relação entre o crescimento do estado do Rio Grande do Sul e o do país e do comércio externo, usa-se a correlação dos principais componentes do PIB do Brasil e do estado gaúcho no período de 2003 a 2015. Os resultados estão reportados na Tabela $10^{2}$. Nota-se que o crescimento do PIB gaúcho apresenta uma alta correlação com o crescimento do PIB brasileiro, que é superior a 0,70, embora a sua participação do total seja em torno de 7\%. Isso demonstra que o desempenho da economia gaúcha possui um forte vínculo com a economia nacional. As variáveis de maior correlação estão entre a importação do Rio Grande do Sul e as importações do Brasil, valor de 0,9835, e as exportações do Brasil, 0,9299. Há também uma alta correlação entre as importações gaúchas e o PIB nacional, que é superior a 0,91 . As exportações brasileiras, por sua vez, apresentam uma correlação de 0,50 de relação com o PIB do RS, e, da mesma forma, a relação das exportações gaúchas com o PIB brasileiro é de 0,54 .

Tabela 10 - Coeficiente de correlação das taxas de crescimento dos principais componentes do PIB do Brasil e do Rio Grande do Sul no período de 2003 a 2015

\begin{tabular}{l|r|r|r|r|r|r}
\hline \multicolumn{1}{c|}{ RS/BR } & \multicolumn{1}{|c|}{ PIB-RS } & \multicolumn{1}{c|}{ AGR-RS } & \multicolumn{1}{c|}{ IND-RS } & \multicolumn{1}{c|}{ SER-RS } & \multicolumn{1}{c|}{ EXP-RS } & \multicolumn{1}{c}{ IMP-RS } \\
\hline PIB - BR & 0,7152 & 0,0392 & 0,8697 & 0,6769 & 0,5402 & 0,9189 \\
AGR-BR & 0,6875 & 0,6442 & 0,6256 & 0,6185 & 0,6364 & 0,5172 \\
IND - BR & 0,694 & 0,0491 & 0,8887 & 0,651 & 0,5717 & 0,9205 \\
SER-BR & 0,6889 & 0,026 & 0,7842 & 0,659 & 0,495 & 0,8316 \\
EXP-BR & 0,5028 & $-0,0263$ & 0,7355 & 0,4757 & 0,562 & 0,9299 \\
IMP - BR & 0,6377 & 0,0525 & 0,8028 & 0,5768 & 0,5977 & 0,9835 \\
\hline
\end{tabular}

Fonte: IBGE/FEE (2015). 
As variáveis que menos se correlacionam são principalmente a exportação do Brasil e o setor de agropecuária do Rio Grande do Sul, com valor negativo de 0,0263. Do ponto de vista setorial, nota-se que o crescimento da indústria do RS está fortemente atrelado ao crescimento da indústria e ao PIB nacional, com correlação de 0,888 e 0,8697 , respectivamente. A indústria gaúcha tem também uma correlação elevada com o crescimento do setor de serviços nacional, que é de 0,7842. Esse resultado indica que boa parte da produção industrial do estado do Rio Grande do Sul é comercializada no restante do país na forma de bens de capital e produtos finais.

A Tabela 11 reporta o coeficiente de correlação das taxas de crescimento do nível de atividades com o comércio exterior do Brasil no período de 2003 a 2015. Observa-se que o desempenho da economia nacional, o PIB, está altamente correlacionado com a dinâmica do comércio exterior, ou seja, a correlação com as importações é de 0,9350 e com as exportações, de 0,8607. Contudo, contrariamente ao esperado, a correlação entre o crescimento do PIB nacional e a taxa de câmbio real é baixa e negativa. Esse fato também é observado para a indústria e o setor de serviços, bem como para as próprias exportações. Isso pode ser explicado pela elevação média dos preços das importações e exportações, que teve uma forte relação positiva com o crescimento da economia brasileira, superior a 0,80; portanto, o crescimento desses preços foi mais relevante para o comércio externo e o incremento do PIB do que a taxa de câmbio real.

Tabela 11 - Coeficiente de correlação das taxas de crescimento do nível de atividades com o comércio exterior do Brasil no período de 2003 a 2015

\begin{tabular}{l|r|r|r|r|r}
\hline \multicolumn{1}{c|}{ BR/BR } & EXPO - BR & IMPO - BR & PREÇO - EXP & PREÇO - IMP & TX- CÂMBIO REAL \\
\hline PIB - BR & 0,8607 & 0,9350 & 0,8627 & 0,8333 & $-0,4410$ \\
AGRO - BR & 0,4863 & 0,5429 & 0,1580 & 0,2140 & 0,3763 \\
IND - BR & 0,9245 & 0,9347 & 0,8198 & 0,8280 & $-0,3669$ \\
SERV - BR & 0,7453 & 0,8560 & 0,8741 & 0,8111 & $-0,5563$ \\
EXPO - BR & 1,0000 & 0,9364 & 0,7601 & 0,8293 & $-0,1877$ \\
IMPO - BR & 0,9364 & 1,0000 & 0,7587 & 0,7942 & $-0,1755$ \\
\hline
\end{tabular}

Fonte: IBGE/FEE (2015).

A correlação das taxas de crescimento do nível de atividades com o comércio exterior para o Rio Grande do Sul, no período de 2003 a 2015, é exibida na Tabela 12. A análise de correlação do estado mostrou claramente o elevado índice de correlação entre o crescimento e o incremento das suas respectivas exportações, com um coeficiente de 0,7238 , e com a taxa de câmbio real também ocorre uma influência inversa. 
Tabela 12 - Coeficiente de correlação das taxas de crescimento do nível de atividades com o comércio exterior do Rio Grande do Sul no período de 2003 a 2015

\begin{tabular}{l|r|r|r|r|r}
\hline \multicolumn{1}{c|}{ RS/RS } & EXPO - RS & IMPO - RS & PREÇO - EXP & PREÇO - IMP & TX - CÂMBIO REAL \\
\hline PIB - RS & 0,7238 & 0,5778 & 0,5441 & 0,5311 & $-0,2462$ \\
AGRO - RS & 0,5015 & 0,0107 & 0,0365 & $-0,0399$ & 0,0329 \\
IND - RS & 0,6971 & 0,7745 & 0,622 & 0,6772 & $-0,2076$ \\
SERV - RS & 0,7833 & 0,5447 & 0,575 & 0,5794 & $-0,3187$ \\
EXPO - RS & 1 & 0,6059 & 0,3971 & 0,6159 & 0,0193 \\
IMPO - RS & 0,6059 & 1 & 0,7601 & 0,7847 & $-0,166$ \\
\hline
\end{tabular}

Fonte: IBGE/FEE (2015).

Salienta-se que o Rio Grande do Sul, em 2015, esteve em terceira posição, representando $9,17 \%$ das exportações brasileiras. Percebe-se, então, que a variável do comércio exterior se torna uma relevante estratégia de desenvolvimento do estado. $\mathrm{O}$ crescimento do comércio exterior do RS mostrou-se bastante correlacionado com o crescimento industrial, apresentando um coeficiente de correlação de 0,6971 para as exportações; 0,7741 para as importações; e acima de 0,60 para os preços dos produtos vendidos e comprados no exterior. Novamente, o setor industrial do estado e a taxa de câmbio real revelaram uma baixa correlação, além de ser contrária. Aliás, os movimentos da taxa de câmbio real apresentaram correlações baixas em relação também às exportações e às importações.

Em 2015, a perda de participação do RS foi marcada pelo período de recessão no país, que provocou uma retração das compras externas do Brasil e do RS. Com base nas correlações apresentadas, pode-se notar de maneira destacável a correlação entre as exportações e as importações do Brasil e o PIB do Rio Grande do Sul, ao mesmo tempo, apresentam-se as exportações e as importações do Rio Grande do Sul, que participam de modo elevado do comércio exterior brasileiro.

\section{Conclusões}

Os desempenhos econômicos do estado do Rio Grande do Sul e do Brasil foram, em geral, bastante positivos ao longo do período de 2003 a 2015. Em termos de participação setorial, os resultados mostram o setor de serviços, em ambos os casos, participando com cerca de $60 \%$ do total, após aparece o setor industrial, com 
tendência de queda, com aproximadamente $25 \%$. A parcela restante ficou por conta do setor agropecuário.

O tamanho da economia do estado gaúcho tem sempre oscilado entre 7,0\% e $8,0 \%$ do total nacional. Em 2014, essa participação caiu para perto de 6\%, mantendo, ainda assim, a quarta posição entre os estados da federação. Quanto ao desempenho, a economia gaúcha apresentou tendência menos oscilatória do que a economia nacional. Contudo, em geral, os resultados revelaram que ambas as economias exibiram uma dinâmica de crescimento do PIB bastante similar, acumulando 32,24\% no período de 2003 a 2014, o que representa também uma média anual de $2,2 \%$.

No que se refere à dinâmica do comércio internacional, os resultados apontam que o crescimento das exportações nacionais e gaúchas foi similar, com uma taxa média anual de aproximadamente 8\%. Já as importações nacionais cresceram mais rapidamente, com quatro pontos percentuais acima das compras externas do RS. Com isso, refletiu-se na redução mais intensa no saldo comercial do país em relação ao estado. Além disso, a economia gaúcha vem se mantendo em destaque entre os maiores exportadores do Brasil, representando, em 2015, 9,17\% das exportações brasileiras, ocupando a terceira colocação entre as unidades da federação.

Dentre os produtos mais exportados pelo estado do Rio Grande do Sul, destacaram-se derivados de soja, fumo, carnes de frango e suína. Os principais mercados de destino desses produtos, em ordem decrescente, foram China, Argentina, Estados Unidos, Coreia do Sul e Vietnã. Já no caso do país como um todo, os produtos do complexo de soja lideram as exportações, seguidos dos segmentos de minérios de ferro, óleos brutos de petróleo, carne de frango, açúcar de cana, concentrando quase a metade da pauta. Os principais destinos foram novamente China, Estados Unidos e Argentina.

A análise de correlação tem relevado uma elevada relação entre o crescimento econômico e o incremento de exportações, com um coeficiente de 0,72 do Rio Grande do Sul e de 0,86 do Brasil. A taxa de câmbio real apresentou uma baixa correlação com a exportações, além de exibir sinal contrário do esperado. Assim, ao longo do período de 2003 a 2015, o que mais tendeu a influenciar o comércio externo foram os preços internacionais dos produtos comercializados.

Por fim, aponta-se como tema de estudos futuros a medição do impacto do comércio exterior sobre o crescimento das economias brasileira e gaúcha. Para isso, podem ser empregados métodos econométricos que considerem a relevância de diversos setores econômicos tanto do país como do estado do Rio Grande do Sul. 


\title{
Un análisis comparativo de la relación entre comercio exterior y crecimiento económico de Rio Grande do Sul y Brasil (2003-2015)
}

\author{
Resumen
}

Este artículo tiene como objetivo analizar la relación entre el $\mathrm{n}$ entre el comercio exterior y el crecimiento económico en Rio Grande do Sul y Brasil durante el período de 2003 a 2015. La metodología utilizada es el análisis de estadísticas descriptivas de datos secundarios extraídos de agencias gubernamentales y instituciones internacionales Los resultados muestran que el tamaño de la economía del Estado representa alrededor del 7\% del total del país, de los cuales, el sector de servicios participa con el 60\%, el segmento industrial como aproximadamente una cuarta parte. La dinámica del crecimiento económico fue bastante similar con una tasa anual promedio de $2.2 \%$. Las exportaciones nacionales y gauchas crecieron, en promedio anual, alrededor del $8 \%$ y las importaciones nacionales aumentaron cuatro puntos porcentuales por encima de RS. La mayor correlación se encontró entre la tasa de crecimiento del producto y el aumento de las exportaciones, con un coeficiente de 0,72 en Rio Grande do Sul y 0,86 en Brasil. El tipo de cambio real mostró una baja correlación como con las exportaciones, además de mostrar un signo contrario a las expectativas. Así, durante el período de 2003 a 2015, lo que más influyó en el comercio exterior fueron los precios internacionales de los productos vendidos.

Palabras claves: Comercio exterior. Crecimiento económico. Economía brasileña. Estado de Rio Grande do Sul.

\section{A comparative analysis of the relationship between foreign trade and economic growth of Rio Grande do Sul and Brazil (2003-2015)}

\begin{abstract}
This paper aims to analyze the relationship between foreign trade and economic growth in Rio Grande do Sul and Brazil from 2003 to 2015. The methodology is the analysis of descriptive statistics of secondary data extracted from government agencies and related international institutions. The results point out the size of the state's economy represents about $7 \%$ of the total of the country, of which the service sector participates with $60 \%$, industrial segment as approximately one quarter. The dynamics of economic growth were quite similar with an average annual rate of $2.2 \%$. National and Gaucho exports grew at an annual average of about 8\% and national imports rose four percentage points higher than RS. The correlation was higher between the growth rate of the product and the increase in exports, with a coefficient of 0.72 for Rio Grande do Sul and 0.86 for Brazil. The real exchange rate showed a low correlation with the exports and exhibited opposite sign than expected. Thus, from 2003 to 2015 , what most tended to influence foreign trade was the international market prices.
\end{abstract}

Keywords: Foreign trade. Economic growth. Brazilian economy. State of Rio Grande do Sul. 
Classificação JEL: E23, F10, F43.

\section{Notas}

1 Alguns estudos que investigam essa temática podem ser consultados em: Averbug (1999), Cândido e Lima (2010), Feder (1983), Feix e Leusin Júnior (2015), Feler (2010), Frankel e Romer (1999), Rodríguez e Rodrik (2001), Sarquis (2011).

2 Detalhamento sobre análise de correlação pode ser encontrado em Fonseca, Martins e Toledo (1985).

\section{Referências}

AGÉNOR, Pierre. R. The economics of adjustment and growth. San Diego: Academic Press, 2000. AVERBUG, André. Abertura e integração comercial brasileira na década de 90. Brasília, DF, 1999. Disponível em: https://web.bndes.gov.br/bib/jspui/bitstream /1408/2972/1/1999_A\%20economia\%20brasileira\%20nos\%20anos\%2090_P.pdf. Acesso em: 15 jun. 2016.

BACEN. Banco Central do Brasil. Relatório Anual, Brasília, v. 47, p. 1-253, 2013. Disponível em: www.bcb.gov.br/pec/boletim/banual2011/rel2011p.pdf. Acesso em: 30 dez. 2016.

BACEN. Banco Central do Brasil. Relatório Anual, Brasília, v. 51, p. 1-248, 2015. Disponível em: www.bcb.gov.br/pec/boletim/banual2015/rel2015p.pdf. Acesso em: 30 dez. 2016.

CÂNDIDO, Marçal S.; LIMA, Fabiano G. Crescimento econômico e comércio exterior: teoria e evidências para algumas economias asiáticas. Revista Economia Contemporânea, Rio de Janeiro, v. 14, n. 2, p. 303-325, 2010. Disponível em: http://www.scielo.br/pdf/rec/v14n2/v14n2a04.pdf. Acesso em: 21 set. 2016.

CAVALCANTE, Thiago; LIMA, Marcos C. A política comercial do governo Lula (2003-2010): uma análise comparativa das relações comerciais do Brasil com o Mercosul e com o resto do mundo. Século XXI, Porto Alegre, v. 4, n. 2, p. 53 -72, jul./dez. 2013.

DUNNING, John H. The eclectic (oli) paradigm of international production: past, present and future. International Journal of the Economics of Business, v. 8, n. 2, p. 173-190, 2001.

FEDER, Gershon. On exports and economic growth. Journal of Development Economics, v. 12, p. $59-73,1983$.

FEE. Fundação de Economia e Estatística. Exportações. 2014. Disponível em: http://www.fee. rs.gov.br. Acesso em: 13 jan. 2017.

FEIX, Rodrigo D.; LEUSIN JÚNIOR, Sérgio. Painel do Agronegócio do Rio Grande do Sul - 2015. Porto Alegre: Fundação de Economia e Estatística; Centro de Estudos Econômicos e Sociais; Núcleo de Estudos do Agronegócio, set. 2015. Disponível em: http://www.fee.rs.gov.br/wpcontent/ uploads/2015/09/20150903painel-do-agronegocio-no-rs-2015.pdf. Acesso em: 20 jan. 2017.

FELER, Rafael D. O comércio internacional como promotor de crescimento econômico: o caso da América do Sul. Revista Brasileira e Economia Contemporânea, v. 4, n. 6, p. 124-154, jun. 2010.

FEM. Forum Econômico Mundial. 2012. Disponível em: https://www.em.com.br/app/noticia/economia/2012/01/25/internas_economia,274272/forum-economico-mundial-2012-discute-reinvencao-das-empresas-para-permanecer-no-mercado.shtml. Acesso em: 21 set. 2016. 
FONSECA, J. S.; MARTINS, G. A.; TOLEDO, G. A. Estatística aplicada. 2. ed. São Paulo: Atlas, 1985.

FRANKEL, Jeffrey A.; ROMER, David. Does trade cause growth? The American Economic Review, v. 89, n. 3, p. 379-399, Jun. 1999.

IBGE. Instituto Brasileiro de Geografia e Estatística. Contas regionais do Brasil: 2010-2013. Rio de Janeiro, 2015. (n. 47: Contas nacionais). Disponível em: http://biblioteca.ibge.gov.br/visualizacao/livros/liv94952.pdf. Acesso em: 17 jan. 2017.

KNIGHT, Gary; CAVUSGIL, S. Tamer; RIESENBERGER, John R. Negócios internacionais: estratégias, gestão e novas realidades. São Paulo: Pearson Prentice Hall, 2010.

KRUGMAN, Paul R.; OBSTFELD, Maurice. Economia internacional: teoria e política. 6. ed. São Paulo: Pearson Addison Wesley, 2005.

LAMAS, Eduardo. Quadro geral do comércio exterior do RS. Indicadores Econômicos FEE, Porto Alegre, v. 35, n. 2, p. 61-76, out. 2007. Disponível em: http://revistas.fee.tche.br/index.php/indicadores/article/viewFile/1561/1929. Acesso: 21 jun. 2016.

LEITZKE, Alexander N.; TRICHES, Divanildo. As exportações dos estados da Região Sul do Brasil por intensidade tecnológica - 1996-07. Ensaios FEE, Porto Alegre, v. 31, n. 1, p. 59-86, ago. 2010.

PEREIRA, Lia V. A China e as exportações brasileiras: perspectivas num cenário de uma nova crise mundial. Revista Comércio Exterior, v. 65, n. 10, out. 2011. Disponível em: http://bibliotecadigital.fgv.br/ojs/index.php/rce/article/viewFile/22931. Acesso em: 01 fev. 2017.

PESSOA, Eneuton; MARTINS, Marcilene. Revisitando a teoria do ciclo do produto. Revista de Economia Contemporânea, Instituto de Economia da UFRJ, v. 11, n. 2, p. 307-29, maio/ago. 2007.

RODRÍGUEZ, Francisco; RODRIK, Dani. Trade policy and economic growth: a Skeptic's Guide to the cross-national literature. Macroeconomics Annual 2000. Cambridge: MIT Press, 2001.

ROMER, Paul M. The origins of endogenous growth. Journal of Economics Perspectives, v. 8, n. 1, p. 3-22, Feb. 1994.

SARQUIS, J. B. Comércio internacional e crescimento econômico no Brasil. Brasília: Fundação Alexandre de Gusmão, 2011. Disponível em: http://funag.gov.br/loja/download/864-com\%C3\%A9rcio-internacional.pdf. Acesso em: 10 fev. 2017.

STORTI, Adriana T.; LANGOSKI, Leandro M.; FLORIANOVITCH, Mônica. As exportações do COREDE norte do Rio Grande do Sul. Perspectiva, Erechim, v. 36, n. 134, p. 125-136, jun. 2012. Disponível em: http://www.uricer.edu.br/site/pdfs/perspectiva/134_276.pdf. Acesso em: 06 out. 2016. 